\title{
On the use of transparent conductive oxides in high concentrator III-V multijunction solar cells
}

\author{
Ignacio Rey-Stolle , Yeonbae Lee , Iván García, Luis Cifuentes \\ Kin Man Yu, Carlos Algora, Wladek Walukiewicz
}

\begin{abstract}
Transparent conductive oxides are commonplace in many PV technologies but have not been applied to III-V multijunction solar cells so far. In this paper, we analyze the current performance of the latest generation of these materials and study the potential advantages of their use in III-V multijunction solar cells via simulations and experiments. Calculations show that a number of conductive oxides have potential for improving the performance of these devices by boosting the lateral conductance of the emitter without significant optical losses. Initial experimental results reveal that there exist a number of practical challenges to be overcome to reach the improvements predicted by theory.
\end{abstract}

\section{INTRODUCTION}

The use of transparent electrodes in electronic devices has experienced a tremendous growth over the last decades. As of today, liquid crystal displays, TFT screens, and a number of different solar cell technologies use transparent electrodes, in particular, those implemented using transparent conductive oxides (TCOs). Focusing on solar cells, and just to name a few examples, Table I presents a summary of the TCOs currently being used or investigated in different PV technologies. As the table shows, Indium Oxides doped with Tin, Gallium or Fluorine are commonplace, and Zinc Oxide and Tin Oxide are also extensively used. Moreover, many other compounds are the subject of intensive research in the lab, in the search for Indium-free alternatives, better conductivities or higher transparencies. Some examples of these include $\mathrm{CdO}$ (both intrinsic and doped with In or Ga) and the multiplicity of ternary compounds that can be formed by mixing the binaries in Table I. Detailed reviews on the application of TCOs in photovoltaic and optoeletronic devices can be found in [1-3].

Despite this evident penetration in most PV technologies, historically TCOs have been deemed of little interest for III-V multijunction solar cells. In short, the reason behind this is the lack of sufficient transparency of the films with the thickness needed to attain high enough sheet conductivity. The common belief is that TCOs typically show low parasitic absorption in a limited and well-defined spectral range, normally encompassing the visible part of the spectrum (i.e. from 400 to $700 \mathrm{~nm}$ ), which is insufficient for devices whose spectral response extends down to $\sim 1850 \mathrm{~nm}$ (i.e. Germanium subcell). Moreover, the need of very high conductivities in the top electrode to minimize the ohmic losses associated with the high current densities produced under concentrator operation made the use of TCOs unfeasible. However, these arguments are starting to be questioned as good transparency in wider spectral ranges and resistivity in the range of $10^{-5} \Omega \cdot \mathrm{cm}$ -just an order of magnitude higher than metals- have been reported $[3,4]$. In this context, the goal of this paper is to present a preliminary assessment about the use of state-of-theart TCOs in III-V multijunction solar cells, in particular in those designed for high concentrator applications. To do so we first analyze through simulations the effects of including TCOs as lateral conducting layers in the front surface of the cell and then we subsequently present the experimental results of the application of TCO thin films onto $\mathrm{GaInP} / \mathrm{Ge}$ dualjunction solar cells.

TABLE I

SOME TRAnSParent CONDUCTIVE OXIDES USED IN SOLAR CELLS

\begin{tabular}{ccc}
\multicolumn{3}{c}{ USED IN SOLAR CELL } \\
\hline TCO & Dopants & PV Technology \\
\hline $\mathrm{In}_{2} \mathrm{O}_{3}$ & $\begin{array}{c}\mathrm{Sn}, \mathrm{Ga}, \\
\mathrm{F}, \mathrm{H}\end{array}$ & $\begin{array}{c}\text { amorphous } \mathrm{Si} \\
\text { CdTe, CIGS } \\
\text { Silicon HIT }\end{array}$ \\
\hline $\mathrm{ZnO}$ & $\mathrm{Al}, \mathrm{In}, \mathrm{Ga}$ & $\begin{array}{c}\text { amorphous Si } \\
\text { CdTe } \\
\text { CIGS } \\
\text { Silicon HIT }\end{array}$ \\
\hline $\mathrm{SnO}_{2}$ & $\mathrm{Sb}, \mathrm{F}$ & $\begin{array}{c}\text { CdTe } \\
\text { Dye sensitized } \\
\text { Perovskite }\end{array}$ \\
\hline $\mathrm{TiO}_{2}$ & $\mathrm{Nb}$ & $\begin{array}{c}\text { CdTe } \\
\text { Dyensitized } \\
\text { Perovskite }\end{array}$ \\
\hline $\mathrm{CdO}$ & $\mathrm{Ga}, \mathrm{In}$ & CdTe \\
\hline
\end{tabular}


TABLE II

IMPACT OF DIFFERENT TCOS ON THE SHORT CIRCUIT CURRENT OF TRIPLE JUNCTION SOLAR CELLS

\begin{tabular}{|c|c|c|c|c|c|}
\hline TCO & $\begin{array}{l}\mathbf{W}_{\text {TCO }} \\
\text { [nm] }\end{array}$ & $\begin{array}{l}\text { RTco } \\
{[\Omega / \square]}\end{array}$ & $\begin{array}{c}\Delta \mathrm{Jsc}, \mathrm{TC} \\
{[\%]}\end{array}$ & $\begin{array}{c}\Delta \mathrm{Jsc}, \mathrm{MC} \\
{[\%]}\end{array}$ & $\begin{array}{c}\Delta \mathrm{Jsc}, \mathrm{BC} \\
{[\%]}\end{array}$ \\
\hline \multirow{3}{*}{$\begin{array}{l}\mathrm{In}_{2} \mathrm{O}_{3}: \mathrm{Sn} \\
\text { ITO } \\
\rho=1.710^{-4} \Omega \cdot \mathrm{cm}\end{array}$} & 12.5 & 120 & 98.9 & 100.3 & 100.7 \\
\hline & 25 & 60 & 97.2 & 99.6 & 99.3 \\
\hline & 50 & 30 & 92.7 & 95.1 & 91.5 \\
\hline \multirow{3}{*}{$\begin{array}{l}\mathrm{ZnO}: \mathrm{Ga} \\
\mathrm{GZO} \\
\rho=4.2 \cdot 10^{-4} \Omega \cdot \mathrm{cm}\end{array}$} & 12.5 & 240 & 98.7 & 100.3 & 100.6 \\
\hline & 25 & 120 & 96.7 & 99.6 & 99.6 \\
\hline & 50 & 60 & 91.3 & 95.4 & 94.0 \\
\hline \multirow{3}{*}{$\begin{array}{l}\mathrm{CdO} \\
\rho=3.5 \cdot 10^{-4} \Omega \cdot \mathrm{cm}\end{array}$} & 12.5 & 280 & 93.8 & 99.8 & 100.1 \\
\hline & 25 & 140 & 87.1 & 99.6 & 100.1 \\
\hline & 50 & 70 & 75.4 & 99.5 & 100.4 \\
\hline \multirow{3}{*}{$\begin{array}{l}\mathrm{CdO}: \mathrm{Ga} \\
\rho=0.8 \cdot 10^{-4} \Omega \cdot \mathrm{cm}\end{array}$} & 12.5 & 120 & 98.3 & 100.2 & 100.7 \\
\hline & 25 & 60 & 96.2 & 100.1 & 100.6 \\
\hline & 50 & 30 & 91.8 & 99.7 & 98.8 \\
\hline \multirow{3}{*}{$\begin{array}{l}\text { CdO:In } \\
\rho=0.5 \cdot 10^{-4} \Omega \cdot \mathrm{cm}\end{array}$} & 12.5 & 40 & 99.1 & 100.3 & 101.0 \\
\hline & 25 & 20 & 97.9 & 100.2 & 100.5 \\
\hline & 50 & 10 & 95.3 & 99.1 & 96.6 \\
\hline
\end{tabular}

The sheet resistances of the TCO layers have been calculated using the representative resistivity values RTco as included in the third column. The columns labeled $\Delta \mathrm{J}_{\mathrm{SC}}$ denote the ratio between the short circuit current produced by the subcell with TCO over that produced by the same subcell without TCO. $\triangle \mathrm{JSC}$ values over $100 \%$ represent situations in which the antireflection performance of the TCO is indeed better than that of the $\mathrm{ZnS}$ layer considered in the reference case.
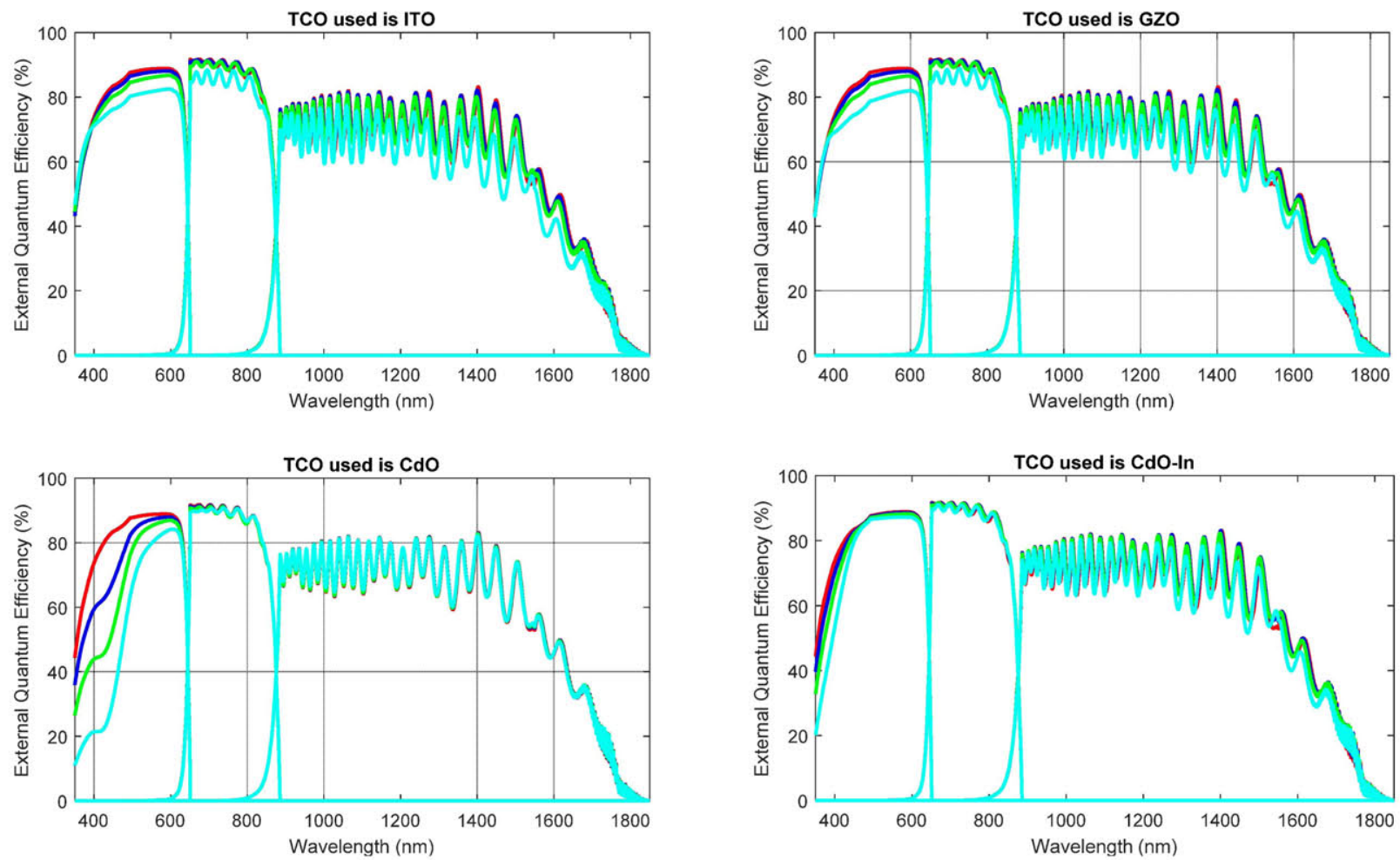

Fig. 1. Simulation of the external quantum efficiency (EQE) of a state-of-the-art triple junction solar cell with different TCOs deposited on the front surfaces. In all graphs the red line corresponds to the solar cell without TCO. The blue, green and cyan lines correspond to solar cells with TCO layers of $12.5 \mathrm{~nm}, 25 \mathrm{~nm}$ and $50 \mathrm{~nm}$. The TCO used in each graph is indicated in a label on top of each graph. 


\section{Performance of Multijunction Solar CEllS WITH TCOS}

Fig. 1 presents the results of the simulation of the external quantum efficiency of state-of-the-art $\mathrm{GaInP} / \mathrm{Ga}(\mathrm{In}) \mathrm{As} / \mathrm{Ge}$ multijunction solar cells with TCOs, using conventional analytic models [5]. In the calculations, the conductive oxide has been placed between the AlInP window layer of the top cell and the antireflection coating. Oxide thicknesses of $0 \mathrm{~nm}$ (i.e. no TCO), $12.5 \mathrm{~nm}, 25 \mathrm{~nm}$ and $50 \mathrm{~nm}$ have been considered. For the cell with no TCO, a simple $\mathrm{MgF}_{2} / \mathrm{ZnS}$ $(100 / 50 \mathrm{~nm})$ has been used. For the cells with TCO, the thickness of the $\mathrm{ZnS}$ layer has been reduced so that $\mathrm{ZnS}$ and TCO thickness add up to $50 \mathrm{~nm}$. A shadowing factor of $8 \%$ has been considered in all cases.

Table II summarizes some properties of the oxides considered and the results in terms of short circuit current quoted as the ratio of the $\mathrm{J}_{\mathrm{SC}}$ of the subcell with TCO over the $\mathrm{J}_{\mathrm{SC}}$ produced by the same subcell without TCO. The analysis of Table II and Fig.1 reveals that the losses for designs using TCO layers of more than $25 \mathrm{~nm}$ are significant, for all the oxide compounds considered. These losses mostly affect the GaInP top cell, and to a lower extent to the $\mathrm{Ga}$ (In)As middle and $\mathrm{Ge}$ bottom subcells (in a similar magnitude in both these subcells). This fact suggest that the most relevant challenge to deal with in order to integrate TCOs in multijunction solar cells is above bandgap absorption and, to a lower extent, free carrier absorption and plasma reflection in the infrared $[4,6]$. However, in the other end, almost all TCOs show moderate losses for thin layers of $12.5 \mathrm{~nm}\left(<2 \%\right.$ in top cell $\mathrm{J}_{\mathrm{SC}}$, and almost no loss in the middle and bottom subcells). Even more so, ITO and CdO:In show drops of top subcell $\mathrm{J}_{\mathrm{SC}}$ below $3 \%$ for $25 \mathrm{~nm}$ thick layers. The point worth noting here is that, even with such thin layers, the sheet resistances achievable are attractive. The sheet resistance of the GaInP top cell emitter in triple junction solar cells is typically in the range of 300$500 \Omega / \square$ (the contribution of the AlInP window is negligible). Hence, values of $\sim 120 \Omega / \square$ (ITO of $12.5 \mathrm{~nm}$ ) or $\sim 40 \Omega / \square$ (CdO:In of $12.5 \mathrm{~nm}$ ) would roughly represent a reduction of the "effective" emitter sheet resistance to a third or a factor of ten, respectively, and would thus contribute to the lateral current spreading, provided that the contact resistance between the AlInP window and the TCO is sufficiently low. Moreover, taking advantage of such low sheet resistances, sparser grids with lower shadowing factor could be used, which would in turn compensate for the loss in $\mathrm{J}_{\mathrm{SC}}$. In this scenario, lower top cell lateral resistances seem within reach without major drops in photocurrent, paving the way for better concentrator performance.

\section{EXPERIMENTAL}

In order to provide an initial validation of the simulation results of figure 1 , we decided to test the use of CdO layers on double junction $\mathrm{GaInP} / \mathrm{Ge}$ structures. On the one hand, according to Table 1, CdO is not the best option but it paves the way to optimize the deposition process for CdO:In or $\mathrm{CdO}: \mathrm{Ga}$, which would provide clearly better results. On the other hand, the use of dual-junction $\mathrm{GaInP} / \mathrm{Ge}$ structures allows monitoring the effects of the TCO on the two most affected subcells, while minimizing the cost and duration of the epi process. Obviously, the next step in this study will be to use $\mathrm{CdO}: \mathrm{In}$ layers on $\mathrm{GaInP} / \mathrm{Ga}(\mathrm{In}) \mathrm{As} / \mathrm{Ge}$ structures.

$\mathrm{GaInP} / \mathrm{Ge}$ solar cell structures were grown in a commercial Aixtron 200/4 MOVPE reactor on p-type Ge(100). Some samples were processed in a conventional way (as controls) whilst in other samples the GaInAs cap layer was chemically etched using $\mathrm{NH}_{4} \mathrm{OH}: \mathrm{H}_{2} \mathrm{O}_{2}: \mathrm{H}_{2} \mathrm{O}$ (2:1:10) leaving the top AlInP window as the front end of the structure. Subsequently, undoped $\mathrm{CdO}$ layers with a nominal thickness of $25 \mathrm{~nm}$ were deposited in a radio frequency magnetron sputtering system under an Ar background pressure of 5 mTorr. Additionally, soda lime glass slides were also used as substrates to measure the optical and electrical properties of the $\mathrm{CdO}$ layers.

On the TCO samples deposited on glass, reflectance and absorptance were measured from 200 to $2500 \mathrm{~nm}$ using a Perkin-Elmer Lambda spectrophotometer. Additionally, the mobility and the electron concentration in the oxide were measured at room temperature by Hall Effect in the Van der Pauw configuration using an Ecopia HMS-3000 system with magnetic fields of $0.5 \mathrm{~T}$ and $1.0 \mathrm{~T}$.

The $\mathrm{TCO} / \mathrm{GaInP} / \mathrm{Ge}$ samples were processed into solar cells using photolithography and electroplated Au contacts. No anti-reflection coating was deposited on the devices. The solar cells followed a standard characterization process including external quantum efficiency, dark and light I-V. Additionally, the reflectance of the solar cell structures was also measured using the same Perkin-Elmer Lambda spectrophotometer.

\section{RESULTS}

\section{A. Optical characterization of the TCOs}

Fig. 2 plots the transmittance of a $25 \mathrm{~nm}$ thick layer of $\mathrm{CdO}$ deposited on glass. The agreement between experiment (black dots) and modelling (blue line) is excellent except for the UV region $(\lambda<430 \mathrm{~nm})$, where $T$ is overestimated.

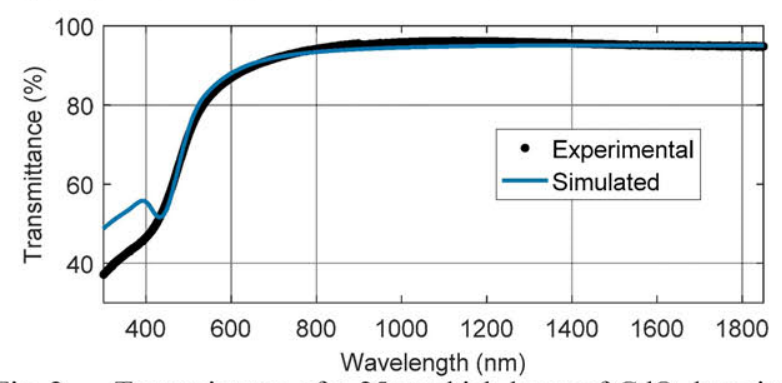

Fig. 2. Transmittance of a $25 \mathrm{~nm}$ thick layer of $\mathrm{CdO}$ deposited on glass. Black dots are experimental data and solid line is the modeling. 

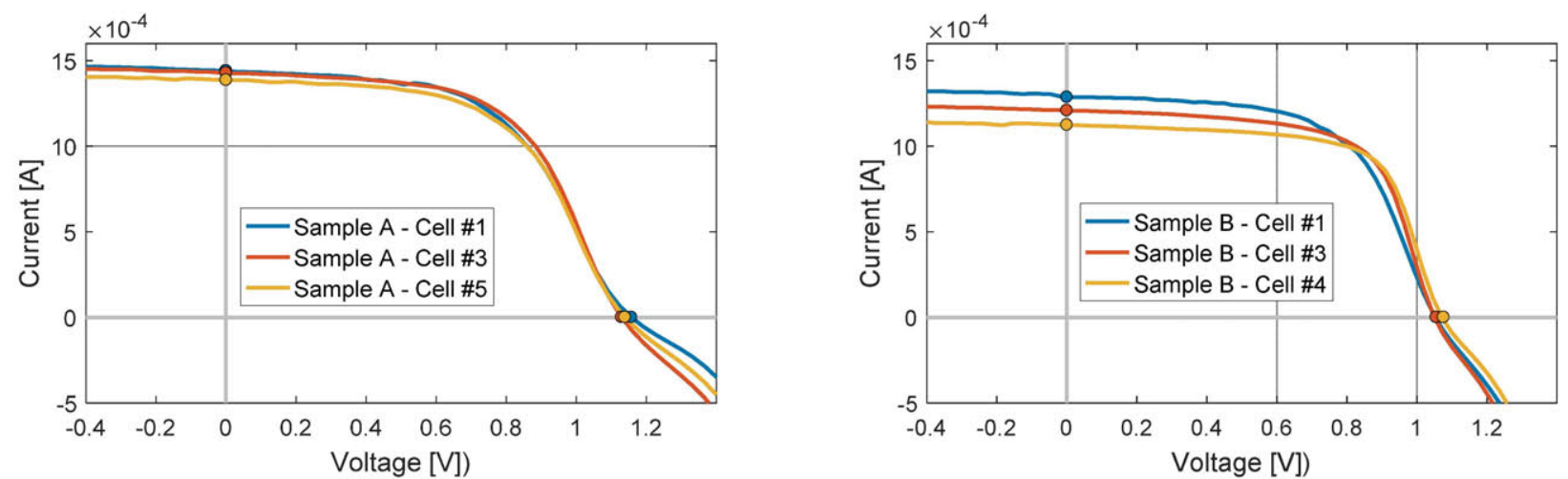

Fig. 3. Light $\mathrm{I}-\mathrm{V}$ curves at one sun of the GaInP/Ge solar cells studied. (Left) three representative devices of sample A (Right) Three representative devices of sample B.
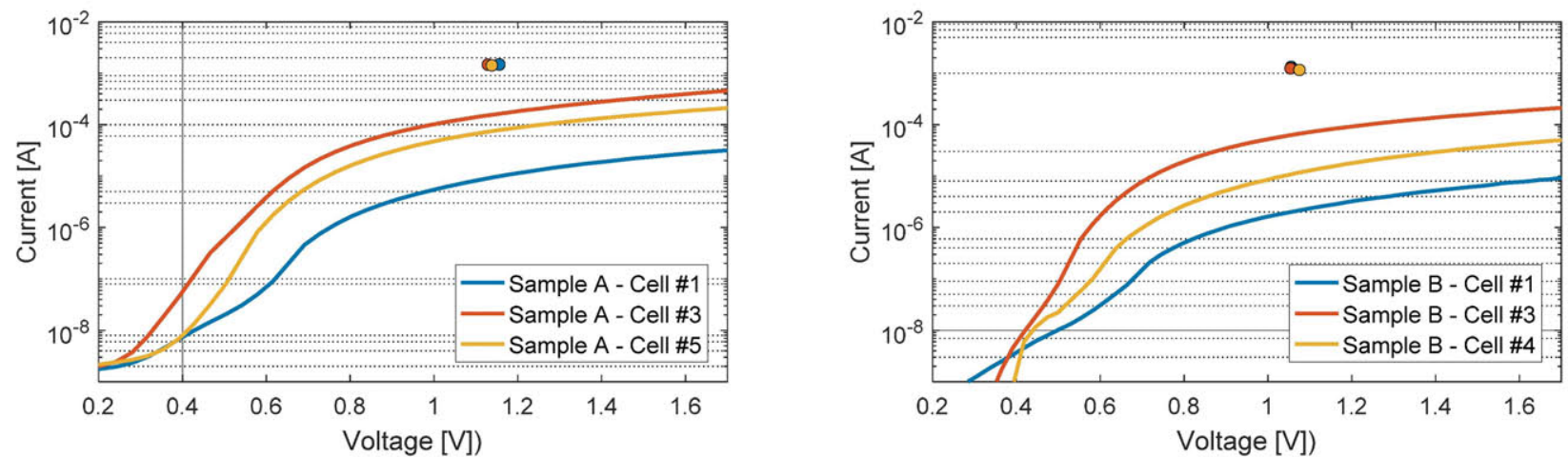

Fig. 4. Dark I-V curves of the GaInP/Ge solar cells studied. (Left) three representative devices of sample A. (Right) Three representative devices of sample B. The devices measured are the same as those included in Fig 3.

\section{B. Electrical characterization of the TCO layers}

The results on the Hall Van der Pauw measurements on the CdO samples deposited on glass are summarized on Table III. These results correspond to the average of several devices per sample. On sample $A$, we obtained a value of carrier concentration lower than expected possibly as a result of $\mathrm{O}_{2}$ contamination in the sputtering process. The problem was solved in sample $B$ that yielded state of the art values for both mobility and carrier concentration (see Table II) [4].

TABLE III

ELECTRICAL CHARACTERIZATION OF THE CdO LAYERS

\begin{tabular}{ccccc}
\hline Sample & $\begin{array}{c}\text { Thickness } \\
{[\mathbf{n m}]}\end{array}$ & $\begin{array}{c}\mu \\
{\left[\mathbf{c m}^{\mathbf{2}} \mathbf{V}^{-\mathbf{1}} \mathbf{s}^{-\mathbf{1}}\right]}\end{array}$ & $\begin{array}{c}\mathbf{n} \\
{\left[\mathbf{c m}^{-3}\right]}\end{array}$ & $\begin{array}{c}\mathbf{R}_{\text {sheet }} \\
{[\Omega / \square]}\end{array}$ \\
\hline $\mathrm{A}$ & 25 & 99 & $7 \cdot 10^{19}$ & 340 \\
\hline $\mathrm{B}$ & 25 & 90 & $1.8 \cdot 10^{20}$ & 154 \\
\hline
\end{tabular}

\section{Light I-V curves}

Fig. 3 shows the I-V curves under one-sun AM1.5d illumination of three illustrative devices in sample A (left graph) and B (right graph). The solar cells plotted were chosen to visually illustrate the device-to-device variability observed in each sample. Table IV summarizes the main solar cell parameters in each sample including the mean ISC and its standard deviation, and the average $\mathrm{V}_{\mathrm{OC}}$ and its standard deviation

Sample A presents a moderate dispersion in the $\mathrm{I}_{\mathrm{SC}}(\sim 2 \%)$; a relative uniformity in the fill factor and a comparatively larger variability in the $\mathrm{V}_{\mathrm{OC}}$. In contrast, Sample B presents a significant variability in the $\mathrm{I}_{\mathrm{SC}}(\sim 7 \%)$, which is in addition $15 \%$ lower than in sample A; a quite variable fill factor; and a significantly lower $\mathrm{V}_{\mathrm{OC}}$. However, the most relevant feature in these curves for both samples A and B is the change in slope in the curve beyond $\mathrm{V}_{\mathrm{OC}}$ that is indicative of a parasitic junction in the structure.

TABLE IV

ONE-SUN I-V CHARACTERIZATION

\begin{tabular}{ccccc}
\hline Sample & $\begin{array}{c}\text { Isc } \\
{[\mathbf{m A}]}\end{array}$ & $\begin{array}{c}\Delta \mathbf{I s c} \\
{[\%]}\end{array}$ & $\begin{array}{c}\text { Voc } \\
{[\mathbf{m V}]}\end{array}$ & $\begin{array}{c}\Delta \mathbf{V o C} \\
{[\mathbf{m V}]}\end{array}$ \\
\hline $\mathrm{A}$ & 1.4 & $2 \%$ & 1.142 & \pm 15 \\
\hline $\mathrm{B}$ & 1.2 & $7 \%$ & 1.063 & \pm 12 \\
\hline
\end{tabular}




\section{Dark I-V curves}

Fig. 4 shows the dark I-V curves for the same three illustrative devices in sample A (left graph) and B (right graph). The colored circles included in the figures are the ISC$\mathrm{V}_{\mathrm{OC}}$ points of each cell obtained from Fig. 3 .

Both samples A and B present a very large dispersion in the reverse saturation current $\left(\mathrm{I}_{0}\right)$ and in the series resistance $\left(\mathrm{R}_{\mathrm{S}}\right)$, with sample B having larger values in both parameters. In both cases, $\mathrm{I}_{\mathrm{SC}}-\mathrm{V}_{\mathrm{OC}}$ points lie far out of their respective dark I$\mathrm{V}$ curves indicating a lack of superposition between dark an illumination. This fact, together with the high series resistance, is again indicative of the presence of a parasitic junction.

\section{E. External Quantum Efficiency}

Fig. 5 depicts the External Quantum Efficiency (EQE) of the GaInP top cells in the three samples studied. The blue line is the reference sample with no $\mathrm{CdO}$ (blue); the red line is sample A and the green line is sample B, both of them with $25 \mathrm{~nm}$ of $\mathrm{CdO}$. The shaded region around the red and green curves represents the variability measured in each sample, which is virtually the same as that measured in the light I-V curves (see Table IV).

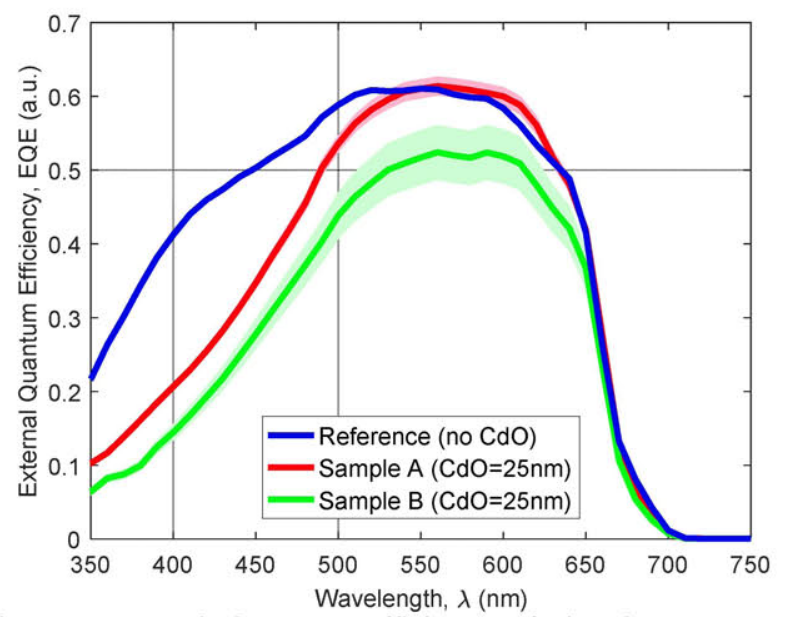

Fig. 5. External Quantum Efficiency of the GaInP top cells studied: Reference device with no CdO (blue); sample A (red) and sample B (green), both with $25 \mathrm{~nm}$ of CdO. The shadowed area represents the variability measured in each sample.

As compared to the reference cell with no $\mathrm{CdO}$, sample $\mathrm{A}$ exhibits the large loss expected from 350 to $500 \mathrm{~nm}$ due to absorption in the $\mathrm{CdO}$, as predicted by the simulations in Fig. 1. The slight improvement from 500 to $650 \mathrm{~nm}$ was also expected as a result of the antireflection role of the TCO. However, a higher EQE was expected for the $25 \mathrm{~nm} \mathrm{CdO}$ deposited, according to our simulations. Concerning sample $\mathrm{B}$, the loss in the whole spectral range is evident, as compared to sample A and the Reference.

\section{F. Characterization of the Metal/TCO and TCO/AlInP contacts}

In addition to solar cells, TLM patterns were also manufactured on the samples to measure the metal/CdO specific contact resistance. The average specific metal/TCO contact resistance between the gold and the $\mathrm{CdO}$ is $2 \cdot 10^{-4} \Omega \cdot \mathrm{cm}^{2}$ in both samples. However, it presents a significant variability with minimum values in the range of $5 \cdot 10^{-5} \Omega \cdot \mathrm{cm}^{2}$ and maximum values around $4 \cdot 10^{-4} \Omega \cdot \mathrm{cm}^{2}$. All contacts were annealed at $200^{\circ} \mathrm{C}$ for $180 \mathrm{~s}$, and no attempt was made to optimize such conditions.

In order to test the current flow between the TCO and the AlInP window, the TLM patterns were etched removing the CdO layer between TLM pads. The CdO layer was still present underneath the pads so current was forced to flow from the $\mathrm{CdO}$ into the AlInP layer to circulate from pad to pad. In this experiment rectifying contacts were measured in all cases, confirming the presence of a non-ohmic junction between the $\mathrm{CdO}$ and $\mathrm{AlInP}$.

\section{DISCUSSION}

The CdO layers deposited on the GaInP/Ge structures have affected severely the light and dark I-V curves of the solar cells at two different levels. On the one hand, the heterojunction formed between the $\mathrm{CdO}$ and the n-AlInP window produces a non-ohmic contact. This was confirmed by TLM measurements and manifests as a variable $R_{S}$ in the dark I-V and a leaky diode in reverse bias in the light I-V. The origin of such is still unclear. No cleaning was performed on the samples prior to $\mathrm{CdO}$ deposition so a thin layer of oxide is assumed to be present at the interface. In addition, the sputtering temperature of $200^{\circ} \mathrm{C}$ or the contact annealing (also at $200^{\circ} \mathrm{C}$ ) might favor further oxidation of the AlInP. Currently, the heterojunction formed between these materials is under investigation to clarify the dependence of this barrier on the doping and Al-content of the AlInP window. On the other hand, the increase and dispersion in the reverse saturation current of the cells observable in the dark I-V seems to suggest that structure has been damaged during the sputtering process. The increased recombination resulting from the damage could account for the losses (and variability) observed in both $\mathrm{I}_{\mathrm{SC}}$ and $\mathrm{V}_{\mathrm{OC}}$. However, the big differences between samples $A$ and $B$, which went through virtually the same sputtering process in terms of power, temperature, duration and distance to the target, seem to indicate that the damage is related to an uncontrolled process variable. At this point, we speculate that the particular position of the sample in the holder plays a role in the final dose of damage received. In this sense, sample A could have received a lower dose of damage and therefore its EQE almost coincides with what simulations predict. Conversely, sample B would have received a higher dose of damage and therefore its $E Q E$ is 
greatly diminished and its reverse saturation current is higher, on average.

\section{SUMMARY AND CONCLUSIONS}

The application of transparent conductive oxides on III-V multijunction solar cells has been studied by simulations and experiments. The impact of including layers of several TCOs on the external quantum efficiency of $\mathrm{GaInP} / \mathrm{Ga}(\mathrm{In}) \mathrm{As} / \mathrm{Ge}$ multijunction solar cells has been analyzed by theoretical simulations using real optical constants of the semiconductor stack and the TCO layers, elucidating the optical losses to be expected. Moderate losses below 2\% are found, mainly in the top cell for thin layers of $12.5 \mathrm{~nm}$ of several TCOs (ITO, GZO, $\mathrm{CdO}: \mathrm{In}, \mathrm{CdO}: \mathrm{Ga}$. However, the electrical properties of such TCO layers offer the possibility of significantly reducing the lateral sheet resistance at the front of the solar cell, which would allow to use sparser grid lines and, hence, reduce the shadowing losses.

Preliminary experiments using undoped $\mathrm{CdO}$ to coat GaInP/Ge solar cells have unveiled challenges to overcome in order to exploit the beneficial properties of TCOs. First, the attainment of an ohmic conduction path between the top cell AlInP window layer has not been achieved using this TCO, which obviously spoils the performance of the solar cell. Second, the sputtering process used to deposit the TCO layers appears to damage the solar cells, which exhibit significantly larger reverse saturation currents. However, expectations to overcome these problems by using doped $\mathrm{CdOs}$ and redesigned deposition conditions are in place.

In summary, the potential of using TCOs in III-V solar cells to assist in the lateral conduction at the front and improve the performance under concentration has been demonstrated, and the preliminary experiments carried out have shown the challenges to overcome and, therefore, have focused the oncoming efforts to be undertaken.

\section{ACKNOWLEDGEMENTS}

This work was supported by the Spanish Ministerio de Economía y Competitividad through projects with code TEC2015-66722-R and projects TEC2014-54260-C3-1-P and by the Comunidad de Madrid through the project MADRIDPV (S2013/MAE-2780). I. García acknowledges the financial support from the Spanish Programa Estatal de Promoción del Talento y su Empleabilidad through the Ramón y Cajal grant with reference RYC-2014-15621. Part of this work was performed at the EMAT, National Center for Electron Microscopy/Molecular Foundry and was supported by the Director, Office of Science, Office of Basic Energy Sciences, Materials Sciences and Engineering Division, of the U.S. Department of Energy under Contract No. DE-AC0205CH11231. W. Walukiewicz acknowledges funding support from the Singapore National Research Foundation (NRF) through the Singapore Berkeley Research Initiative for Sustainable Energy (SinBeRISE) Programme

\section{REFERENCES}

[1] E. Fortunato et. al, 'Transparent Conducting Oxides for Photovoltaics', MRS Bulletin, 32(3), pp. 242-247 (2007)

[2] A. Klein, et al. "Transparent Conducting Oxides for Photovoltaics: Manipulation of Fermi Level, Work Function and Energy Band Alignment', Materials 3, 4892-4914; (2010)

[3] M. Morales-Masis, et al. "Transparent Electrodes for Efficient Optoelectronics", Adv. Electron. Mater. 2017, 3, 1600529.

[4] K. M. Yu, et al, "Ideal transparent conductors for full spectrum photovoltaics", Journal of Applied Physics 111, 123505 (2012)

[5] I. Rey-Stolle, J. M Olson, C. Algora "Concentrator Multijunction Solar Cells", Chapter 2 of Handbook of Concentrator Photovoltaic Technology, John Wiley, 2016

[6] D. S. Ginley and J. D. Perkins, in Handbook of Transparent Conductors, edited by D. S. Ginley, (Springer, 2010), Chapter 1 